while concentrations of $0.001,0.1$ and $1.0 \mathrm{mgm} . / 1$. were without effect. However, after about thirty days, vigorous growth commenced in the medium originally containing $10 \mathrm{mgm} . / \mathrm{l}$. indole-3-acetic acid and proceeded at the same rate as in its absence. It seems probable that this was due to inactivation of the indole-3-acetic acid by the small amount of mycelium formed. It is suggested that indole-3acetic acid may play a part in the growth processes of this fungus similar to that in higher plants, although the possibility that some related substance such as tryptophan is required for growth must also be considered, particularly in view of the unidentified growth-promoting factor present in various extracts.

\section{Dissemination of Rust Fungi in India}

IN Scientific Monograph No. 18, published in 1952 by the Indian Council for Agricultural Research, Prof. Mehta, of Agra College, has presented a detailed account of a study of the dissemination in India of three rusts of wheat and barley, Puccinia graminis tritici, $P$. triticina and $P$. glumarum. The work was carried out mainly between the years 1932 and 1938 and is a continuation of that reported earlier in Monograph No. 14. By means of slide traps on stationary aeroscopes or on kites, balloons or aeroplanes in the vicinity of some twenty stations throughout the country, Prof. Mehta has compiled estimates of the aerial distribution of the fungi and related these data to the trajectories of relevant winds and the incidence of disease outbreaks. The results, presented as a series of maps and tables in the monograph, showed that spore showers preceded outbreaks of rust at most stations and that winds usually came from places where the diseases had been prevalent from fifteen days to two months previously. Such sources of inoculum usually originated in the hills, where an early crop was some. times grown or developed from tillers or self-sown plants, becoming infected earlier than that in the plains. These findings are discussed and the conclusion reached that the most important foci for the dissemination of rust inoculum lie in central Nepal, the Nilgiris and the Palni hills, and that early spread from these regions to the Indo-Gangetic plain and Peninsular India, respectively, is chiefly responsible for outbreaks experienced there. In as final section the author briefly reviews the situation and makes proposals for the control of these rusts in India. Measures recommended for specified hill regions include suspension of the early crops of wheat and barley, destruction of self-sown plants and stray tillers between seasons and postponement of sowing to coincide with that in the plains.

\section{Graphs of the Compton Energy-Angle and the Klein-Nishina Formula}

Crrcutar 542 of the National Bureau of Standards, Washington, D.C., is primarily a representation in graphical form, by Ann T. Nelms, of the Compton energy-angle relationship and the differential and integral Klein-Nishina cross-sections as functions of the energy and direction of the scattered photon and of the recoil electron (pp. iv +89 . Washington : Government Printing Office, 1953 ; 55 cents). Unpolarized primary gamma-rays in the energy-range $10 \mathrm{keV} .-500 \mathrm{MeV}$. are considered. It is stated that interpolated values may be obtained from the curves with an accuracy of 2 per cent. The data are expressed in the units used most often by experimentalists and are based on DuMond and Cohen's (1951) values of the fundamental constants. The graphs are preceded by a discussion of the various experimental, theoretical and mathematical considerations involved in the relationships finally chosen for computation and representation. The Circular represents the fourth item in a series of surveys and tabulation of information on radiation physics carried out with the support of the Biophysics Branch of the United States Atomic Energy Commission. The three previous items have been given limited circulation.

\section{Webster Plass Collection of African Art}

The late Mr. Webster Plass, of Philadelphia, and his wife collected for many years examples of African works of art. Mr. Plass always wished that his collection would eventually find a permanent home in the British Museum, and Mr. William Fagg, assistant keeper in the Department of Ethnography, has now compiled a memorial catalogue of the collection. Bearing the title "Webster Plass Collection of African Art" and the sub-title "Catalogue of a Memorial Exhibition held in the King Edward VII Galleries of the British Museum", this catalogue has been published by the British Museum, the cost having been borne by Mrs. Plass (pp. $47+46$ plates; 1953). There are forty-six pages of illustrations of works of art made by various Central and West African peoples, and these are described in detail in the catalogue. There is also a map showing the distribution of their makers. The whole is well and clearly set out, and Mr. Fagg is to be congratulated on his work. It is a pity, perhaps, that the paper on which the half-tones are printed could not have been of a rather better quality. The reproductions are good but could have been even better. There is a short introduction on African art in general.

\section{Stanford University Natural History Museum}

THE main fish and herpetological collection rooms of the Natural History Museum of Stanford University have recently been entirely refitted at $a_{0}$ total cost of 30,000 dollars, 93 per cent being raised by a graduate students' Zoology Project Fund to which many graduates and friends of the University have contributed. The fish collections have been supplied with $9,000 \mathrm{sq}$. ft. of new steel-shelving which will increase the fish research space by two-thirds. Modern lighting has been installed and also a new electric 'dumb waiter' to connect the double-decked fish collection with other floors in the building, so that the Stanford collection, which contains about 750,000 specimens, is now one of the best-housed in the world. It has also been possible to utilize the old shelving for renovating the herpetological collection facilities, thus increasing their shelf-space by 100 per cent.

\section{Industrial Relations and Human Relations}

IN an address on January 20, 1954, to the Birmingham branch of the Institute of Personnel Management, Sir Godfrey Ince, permanent secretary to the Ministry of Labour and National Service, concluded that although. we have gone a long way towards establishing good industrial relations and constitutionalism in British industry and have made great progress in good labour relations techniques, "we have not yet gone very far in tackling the problem underlying good human relations, the problem of securing the right attitude of mind in industry". The address is printed in the latest issue of the Institute's journal, which also contains an important article on joint 